\title{
Cost of surgical intervention for reconstructive therapy of HIV-associated facial lipoatrophy
}

This article was published in the following Dove Press journal:

Patient Preference and Adherence

16 May 201I

Number of times this article has been viewed

\section{Massella' \\ J Ivanovic ${ }^{2}$ \\ R Bellagamba ${ }^{2}$ \\ R De Vita ${ }^{3}$ \\ L Fracasso $^{3}$ \\ $\checkmark$ Tozzi $^{2}$ \\ V Fragola' \\ M Rizzica ${ }^{2}$ \\ P Narciso ${ }^{2}$}

'Istituto Superiore Sanità, Rome, Italy; ${ }^{2}$ National Institute for Infectious Disease - Lazzaro Spallanzani, Rome, Italy; ${ }^{3}$ Regina Elena National Cancer Institute of Rome, Italy
Correspondence: Maurizio Massella Istituto Superiore Sanità, Viale Regina Elena 29900161 - Roma, Italy

$\mathrm{Tel}+39064990330$ I

Fax +390649387199

Emailm.massella@iss.it
Abstract: This study aims to assess direct cost of reconstructive interventions with facial fillers for treatment of HIV (human immunodeficiency virus)-associated facial lipoatrophy (FLA). Evaluation was performed on data from patients enrolled in one arm of a comparative study of immediate versus delayed reconstructive treatment of facial lipoatrophy. Median costs were standardized for efficacy, estimated using data reported by physicians and patient reported outcomes. The variations of the results were evaluated with a sensitivity analysis. Evaluation was performed on 66 patients characterized by significant differences in terms of severity of FLA. Total cost resulted of $€ 140,416.15$, with a median cost per patient of $€ 2126.04$ (interquartile range [IQR]: 1599-2822). Taking into consideration severity of disease, median costs were $€ 1641.67$ (IQR: 1326.67-2126.04) and 2557.12 (IQR: 1939.34-2872.04) $(P=0.0)$ respectively for patients with low and high severity scores at baseline. Significant differences in term of cost-effectiveness ratios were also found between patients with different severity of FLA, and sensitivity analysis showed that these ratios increase with higher severity scores at baseline and vary widely depending on the costs of filler. Although these results cannot be considered representative because of important limitations, the present study suggests the severity of disease as an important determinant of costs.

Keywords: dermal fillers, antiretroviral therapy, lipodystrophic syndrome, HAART

\section{Introduction}

Lipodystrophic syndrome (LDS) is characterized by body fat alterations and metabolic abnormalities ${ }^{1}$ and is a common and highly worrying long-term complication of people living with human immunodeficiency virus (HIV) infection taking highly active antiretroviral therapy (HAART). One of the most distressing expressions of LDS is facial lipoatrophy (FLA), defined as the loss of facial fat, including the buccal fat and temporal fat pads, which leads to facial skeletonization with concave cheeks, prominent nasolabial folds, periorbital hollowing, and visible facial musculature. ${ }^{2}$ Changes in body image may result in self-esteem reduction, poor adherence to therapeutic schedule, and social withdrawal due to the stigma related to disclosure of HIV-status. ${ }^{3}$ The poor knowledge about pathogenesis and progression of LDS limits the implementation of therapeutic strategies to properly face its management. ${ }^{4}$ To date, poor results have been obtained with current therapeutic approaches. Drug switching from stavudine or zidovudine to abacavir or tenofovir provides only limited benefits, while change in life habits, such as diet or physical exercise, have almost no efficacy. ${ }^{5}$ Novel antidiabetic drugs, glitazones, cause little improvement in HAART-associated lipoatrophy, but increase blood cholesterol and triglyceride concentrations significantly, and thus cannot be recommended. ${ }^{6}$ 
Some new approaches including uridine supplementation and use of adipocytokines, growth hormone, metformin, and statins (alone or in combination) merit further investigation. ${ }^{7}$ Autologous fat transfer has been used successfully to improve the appearance in patients with FLA, ${ }^{8}$ but it is a more invasive surgical procedure than injections of facial fillers.

Interest in surgical interventions with facial fillers for correction of FLA has recently been growing, as they are minimally invasive and appear to give an immediate psychological relief to the patient. ${ }^{5}$ Among the commonly used facial fillers, encouraging results have been achieved with poly-L-lactic acid (PLA) (Sculptra $\left.{ }^{\circledR} 2004\right),{ }^{9}$ a biodegradable, synthetic polymer, and with polyacrylamide gel (PAIG) (Aquamid ${ }^{\circledR}$ 2005), ${ }^{10}$ an immunologically inactive, nonresorbable filler.

The present study aims to assess the monetary cost of the surgical correction of HIV-related FLA by injections with the abovementioned facial fillers using data from a clinical study. ${ }^{11}$

\section{Methods}

\section{Study design and aim}

Evaluation was performed using data from one arm of a comparative open-label study of immediate versus delayed reconstructive treatment for antiretroviral-associated FLA with PLA or PAIG. ${ }^{11}$ For the present analysis, we only used data from the immediate treatment group (ITG) of such randomized open-label study. ITG patients were monitored for a 24-week period. Total costs to sustain the surgery correction were calculated for each patient and then standardized for efficacy expressed as reduction of FLA grade; subsequently, both costs and cost/efficacy ratios were calculated taking into account the severity scores at baseline. Based on severity score as reported by the surgeon, the population was divided into "low severity" (grade 1-3), and "high severity" (grade 4-5).

\section{Patients}

In the main study were enrolled patients with the following inclusion criteria: 18 years of age or older; HIV-related LDS with moderate and severe FLA (evaluated by surgeon) and eligible for corrective surgical intervention on the basis of surgeon's opinion; CD4 $>100 / \mathrm{mm}^{3}$; HIV-RNA $<1000$ copies/mL; stable HAART for at least 6 months. Exclusion criteria included pregnancy, previous treatment with dermal fillers, current anticoagulant or cortisone treatments, AIDS dementia complex, unstable diabetes mellitus, skin diseases (such as herpes, psoriasis, and any dermatitis in active phase), dental treatments, no good clinical condition. All individuals eligible for FLA treatments were offered detailed descriptions of product characteristics, and the choice of filler was made according to experience of surgeon and patient's preference. All the participants were enrolled by a single large Italian clinical center: the National Institute for Infectious Diseases "L. Spallanzani", Rome, and a written informed consent was signed by each patient.

\section{Costs}

Only direct costs were taken into consideration and were costs for surgeon, surgeon's assistant, surgery supplies, and fillers. Cost of the surgeon was estimated considering the annual costs and total number of applications; costs of the assistant of the surgeon was calculated considering the annual costs and the time necessary to perform the intervention. Costs of disposable materials were computed considering the unit costs and the amount used during the clinical trial; costs of fillers were expressed taking into consideration total number of vials used. Costs of adverse events were not estimated because they resolved spontaneously without any therapeutic intervention (pharmacological or surgical). Evaluations have been conducted from the service supplier's perspective, and because of the short follow-up period, discounting was not applied.

\section{Effectiveness}

The efficacy of facial fillers was expressed in terms of percentage of change, from baseline to the end of corrective intervention, of severity grade of FLA assessed by both physician and patient. The change in FLA grading score determined by the physician was estimated using a validated FLA severity scale, which ranged from grade 1 (mild lipoatrophy) to grade 5 (the most severe lipoatrophy). ${ }^{12}$

The change in FLA grading score as determined by the patient was evaluated using a severity scale, which provides standardized scores: none (0), mild (1), moderate (2), and severe (3). ${ }^{13}$

\section{Dermal fillers for lipoatrophy correction}

Dermal fillers used were PAIG (Aquamid ${ }^{\circledR}$, Contura, Soeberg, Denmark) and PLA (Sculptra ${ }^{\circledR}$, Aventis Pharmaceutical, Collegeville, PA) dermal fillers.

PAIG is an injectable hydrogel implant composed of $97.5 \%$ apyrogenic water bound to $2.5 \%$ cross-linked polyacrylamide. It is a permanent filler and is nonresorbable, nonallergenic, physically and chemically stable, and immunologically inactive. It is available in two variants Aquamid and Aquamid Reconstruction (made with higher viscosity for treatments that require more volume), 
both in $1 \mathrm{~mL}$ pre-filled syringes. ${ }^{14}$ Sculptra $^{\circledR}$ (PLA) is an injectable implant and contains microparticles of poly-L-lactic acid, a biocompatible, biodegradable, synthetic polymer from the alpha-hydroxy-acid family. It is reconstituted at least 2 hours prior to use by the addition of $4-6 \mathrm{~mL}$ of sterile water for injection to form a sterile suspension. PLA works to stimulate a progressive increase in dermal thickness. ${ }^{15}$

Patients received a set of 2-5 injections, with a 4-week period between two injections. At each surgery session, the specific facial morphologic features of the patients were carefully analyzed before the injection of fillers, and color digital photographs were collected before and after each injection session. Neither prophylactic antibiotics nor local anesthesia was administered preoperatively. At each injection session, patients received several injections into and around the deep dermis of the atrophied perimalar area. The injected quantity of material depended on the severity of skin depression. The treatment was discontinued if any adverse reaction had occurred following the injection.

\section{Data collection}

Study entry demographic data included gender, age, and route of transmission. Baseline clinical information included duration of HIV disease, HIV disease stage (Centers for Disease Control and Prevention [CDC]), HIV RNA viral load, CD4+ cell count, and years of previous antiretroviral therapy (ART). FLA severity grades were collected at baseline and at the end of the treatment.

\section{Statistical analysis}

Baseline characteristics of demographic and clinical variables were reported; median costs were calculated and then standardized for efficacy and reported for both surgeons and patients.

A sensitivity analysis was performed using a linear regression model in order to explore the changes of the resulting cost efficacy $(\mathrm{C} / \mathrm{E})$ ratios when varying the cost of fillers and severity scores at baseline. Cost of fillers and severity scores at baseline were the independent variables introduced in the linear regression model, which in a preliminary

Table I Baseline characteristics

\begin{tabular}{|c|c|c|c|c|}
\hline & All & Low severity & High severity & $P$-value \\
\hline $\mathrm{N}$ & 66 & 29 & 37 & \\
\hline \multicolumn{5}{|l|}{ Sex } \\
\hline Male n (\%) & $56(84.8)$ & 21 & 35 & $0.017^{\mathrm{a}}$ \\
\hline \multicolumn{5}{|l|}{ Age } \\
\hline Mean \pm SD & $44.48 \pm 5.8$ & $43.4 I \pm 5.48 I$ & $45.32 \pm 5.991$ & $0.58^{\mathrm{b}}$ \\
\hline Median (IQR) & $43.00(42-47)$ & $43.00(40.0-46.5)$ & $43.00(42.0-48.5)$ & \\
\hline \multicolumn{5}{|c|}{ Risk factor n (\%) } \\
\hline Homosexual & $26(33.3)$ & 12 & 14 & $0.904^{a}$ \\
\hline Drug user & $18(39.4)$ & 7 & 11 & \\
\hline Heterosexual & $22(27.3)$ & 10 & 12 & \\
\hline \multicolumn{5}{|l|}{ CD4 } \\
\hline Mean \pm SD & $663.53 \pm 320.874$ & $707.03 \pm 333.331$ & $629.43 \pm 311.067$ & $0.629^{b}$ \\
\hline Median (IQR) & $602.50(437.75-799.50)$ & $626.00(445.5-849.5)$ & $565.00(403.5-737.0)$ & \\
\hline \multicolumn{5}{|c|}{ HIV RNA (log) } \\
\hline Mean \pm SD & $1.9677 \pm 69354$ & $1.8519 \pm 0.53101$ & $2.0584 \pm 9367$ & $0.38^{\mathrm{b}}$ \\
\hline Median (IQR) & $1.69(1.69-1.69)$ & $1.69(1.69-1.69)$ & $1.69(1.69-1.86)$ & \\
\hline \multicolumn{5}{|l|}{ Stage n (\%) } \\
\hline CDC A & $6.00(9.10)$ & 4 & 2 & $0.737^{a}$ \\
\hline$C D C B$ & $36.00(54.6)$ & 16 & 20 & \\
\hline CDC C & $24.00(36.4)$ & 9 & 15 & \\
\hline \multicolumn{5}{|c|}{ Time from HIV diagnosis (years) } \\
\hline Mean \pm DS & $12.86 \pm 4.917$ & $12.72 \pm 4.165$ & $12.97 \pm 5.490$ & $0.126^{b}$ \\
\hline Median (IQR) & $12.00(10.00-15.25)$ & $12.00(\mid 0.5-15.5)$ & $12.00(9.5-16.5)$ & \\
\hline \multicolumn{5}{|c|}{ Time from lipodystrophy syndrome } \\
\hline Mean \pm SD & $5.14 \pm 2.259$ & $5.00 \pm 2.171$ & $5.24 \pm 2.350$ & $0.742^{b}$ \\
\hline Median (IQR) & $5.00(3.00-6.25)$ & $5.00(3.0-6.5)$ & $5.00(3.0-6.5)$ & \\
\hline \multicolumn{5}{|c|}{ Years on ART } \\
\hline Mean \pm SD & $9.45 \pm 2.943$ & $9.33 \pm 2.707$ & $9.55 \pm 3.149$ & $0.606^{\mathrm{b}}$ \\
\hline Median (IQR) & $10.00(7.875-10.250)$ & $10.00(7.5-10.5)$ & $10.00(7.75-10.5)$ & \\
\hline
\end{tabular}

Notes: ${ }^{a} \chi^{2}$ test; 'btudent's $t$-test.

Abbreviations: ART, antiretroviral therapy; CDC, Centers for Disease Control and Prevention stage; HIV, human immunodeficiency virus; IQR, interquartile range; RNA, ribonucleic acid; SD, standard deviation. 
Table 2 Facial lipoatrophy severity score at baseline

\begin{tabular}{lll}
\hline & Surgeon reported & Patient reported \\
\hline Grade 2 & 10 & 38 \\
Grade 3 & 19 & 28 \\
Grade 4 & 31 & \\
Grade 5 & 6 & \\
\hline
\end{tabular}

univariate analysis showed significant correlations with $\mathrm{C} / \mathrm{E}$ ratios (calculated using efficacy data reported by surgeons) as dependent variables.

The variations of independent variables was $\pm 20 \%$ for filler costs and grade 1 and grade 5 for severity scores at baseline. Cost of care technique was used to evaluate shortterm costs of surgical correction of FLA.

\section{Results}

\section{Baseline characteristics}

Analysis was conducted on 66 of 67 patients that were included in the ITG arm of the main clinical trial. In this population, mean time from HIV diagnosis was $12.9 \pm 4.9$ years, mean time from lipodystrophy syndrome $5.1 \pm 2.3$ years, and mean time on ART was $9.4 \pm 2.9$ years (Tables 1 and 2 ).

\section{Efficacy}

The patients enrolled received an average of four filler applications (range 2-5) over a mean period of 21 weeks (range 7-55). Changes from baseline to the end of surgical intervention were different depending on the evaluation performed by physicians or patients. Physicians reported a mean change of $86.38 \pm 20.34$ and a median change of 100 (interquartile range [IQR]: 75-100). Patient-reported evaluation showed a mean change of $79.38 \pm 31.23$, while the median change was 100 (IQR: 50-100) (data not shown).

\section{Costs and cost-effectiveness}

Total cost to sustain the FLA treatments for 66 patients was $€ 140,416.15$, with a median cost for patients of $€ 2126.04$ (IQR: 1599.90-2822.17).
Total cost of surgeon for 272 applications (PAIG $=134$ and PLA $=138$ ) was $€ 9000$; cost of assistant of surgeon was $€ 1846.88$, considering a mean time of 30 minutes for intervention. Costs and number of fillers for PAIG were significantly higher than PLA (Table 3). After stratification for severity of disease, resulting total median costs were significantly different; for patients with low severity score at baseline, median costs were $€ 1641.67$ (IQR: 1326.67-2126.04); median costs of patients with high severity of disease were $€ 2557.12$ (IQR: 1939.34-2872.04). Median C/E ratios based on efficacy reported by physicians were $€ 17.19$ (IQR: 13.26-25.00) and $€ 28.82$ (IQR: 23.23-37.62) respectively for low and high severity scores. When efficacy was calculated on data reported by patients, resulting median $\mathrm{C} / \mathrm{E}$ ratios were 23.57 (IQR: 14.53-33.60) and 31.47 (IQR: 23.03-41.19) respectively for low and high severity scores (Table 4).

\section{Sensitivity analysis}

Nonstandardized coefficients of the linear regression model were $\beta_{1}=0.011$ for cost of fillers, $\beta_{2}=5.537$ for lipodystrophy severity scale at baseline, with a constant value of -11.918 . When baseline severity score was grade 1 , the resulting $\mathrm{C} / \mathrm{E}$ ratios were $€ 10.25$ and $€ 18.56$; $\mathrm{C} / \mathrm{E}$ ratios of $€ 32.39$ and $€ 40.73$ were found when the severity at baseline was grade 5 .

\section{Discussion and conclusion}

FLA is a long-term toxicity associated with HAART for treatment of people with HIV infection, and corrective interventions with facial fillers for HIV-associated FLA represent an important approach to treat this clinical condition. This study aims to assess direct costs of reconstructive surgery.

$\mathrm{C} / \mathrm{E}$ ratios increase with higher grade of FLA and vary widely depending on the costs of fillers as showed by sensitivity analysis; these results cannot be considered representative of all people with HIV infection affected by FLA because the sample size is not large enough; another limitation is the subjective assessment of FLA other than the short follow-up. Despite these limitations, the suggestion

Table 3 Cost and utilization of fillers

\begin{tabular}{lllll}
\hline & All & PAIG & PLA & P-value $^{\mathbf{a}}$ \\
\hline $\mathrm{N}$ of fillers & 531 & $296^{\mathrm{b}}$ & 235 & \\
Median fillers (IQR) & $8.0(6-10)$ & $9.5(7.75-10)$ & $7.0(6-9)$ & 0.03 \\
Total costs of filler & 128742.45 & 79392.45 & 49350.00 & $1470.00(1260-1890)$ \\
Median cost of filler & $1890(14 \mid 7-2650.5)$ & $2517.97(2054.13-2710.35)$ & $840.0-2730.0$ & 0.00 \\
(IQR) min-max & & $795.15-3790.00$ & 800 \\
\hline
\end{tabular}

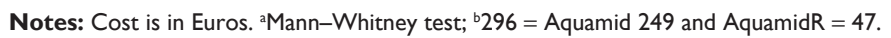

Abbreviations: IQR, interquartile range; PAIG, polyacrylamide gel; PLA, poly-L-lactic acid. 
Table 4 Cost and C/E ratios

\begin{tabular}{|c|c|c|c|c|}
\hline & All & Low severity & High severity & $P$-value ${ }^{a}$ \\
\hline Total cost & 140,416 & $50,469.76$ & $89,946.39$ & 0.00 \\
\hline \multicolumn{5}{|l|}{ Cost } \\
\hline Median (IQR) & $2126.04(1599.90-2822.17)$ & $164 \mid .67(|326.67-2| 26.04)$ & 2557.12 (1939.34-2872.04) & 0.00 \\
\hline \multicolumn{5}{|c|}{ C/E ratio (physician) } \\
\hline Median (IQR) & $25.13(16.4 I-32.83)$ & $17.19(13.26-25.00)$ & $28.82(23.23-37.62)$ & 0.00 \\
\hline \multicolumn{5}{|c|}{ C/E ratio (patient) } \\
\hline Median (IQR) & $28.62(18.50-38.80)$ & $23.57(14.53-33.60)$ & $31.47(23.03-41.19)$ & 0.03 \\
\hline
\end{tabular}

Notes: Cost is in Euros. ${ }^{a}$ Mann-Whitney test.

Abbreviations: $C / E$, cost/efficacy; IQR, interquartile range.

of severity of disease is consistent with data from another study, where association between lipodystrophy assessment score with health care costs and utilization was observed, ${ }^{16}$ showing lipodystrophy severity as an important predictor of health care expenditures. The observational period of 24 weeks doesn't permit to estimate the costs completely because of retreatments caused by durability of the corrections. The persistency of efficacy determining the aesthetic benefits and thus the number of applications and of fillers could change the economic weight of these interventions. Differences in the persistency of efficacy depend on the nature of the fillers; ${ }^{17}$ the use of biodegradable products, like PLA, is usually limited by their short durability while nonbiodegradable fillers, like PAIG ${ }^{18}$ are characterized by prolonged permanence. Although the surgical correction of FLA doesn't invariably result in a positive impact on psychosocial wellbeing and on health related quality of life, ${ }^{11}$ it determines a clinical improvement of FLA severity as reported by both physician and patient. Patient-reported outcomes reflect the patient's own perception of the improvement, thus expressing a positive effect as supported by results on patient satisfaction reported in the literature. ${ }^{19}$

The heterogeneity and complexity of this clinical condition require a multidisciplinary approach. In this scenario, an important role is played by evaluation of costs also because this type of intervention is not assured by national health services. Our contribution consists of describing cost and $\mathrm{C} / \mathrm{E}$ ratios, suggesting the "severity score" is a determinant of cost of these interventions. To date, few data on costs are available, so further studies with more adequate sample sizes, and longer observational periods, need to be implemented to improve the knowledge of the pharmacoeconomics of FLA corrective interventions. Such surgical procedures may open promising perspectives to face lipodystrophy in the management of HIV-infection, providing policy makers with an additional tool to properly address, also in terms of costs, the effects of this serious complication of ART.

\section{Disclosure}

The authors report no conflicts of interest in this work.

\section{References}

1. Hengel RL, Watts NB, Lennox JL. Benign symmetric lipomatosis associated with protease inhibitors. Lancet. 1997;350:1596.

2. Garg A. Acquired and inherited lipodystrophies. N Engl J Med. 2004; 350:1220-1234.

3. Oette M, Juretzko P, Kroidi A, et al. Lipodistrophy syndrome and self-assessment of well being and physical appearance in HIV-positive patients. AIDS Patient Care STDS. 2002;16:413-417.

4. Kotler DP, Rosenbaum K, Wang J, Pierson RN. Studies of body composition and fat distribution in HIV-infected and control subjects. J Acquir Immune Defic Syndr Hum Retrovirol. 1999;353(9170): 2093-2099.

5. Lundgren JD, Battegay M, Behrens G, et al. European AIDS Clinical Society (EACS) guidelines on the prevention and management of metabolic diseases in HIV. HIV Med. 2008;9:72-81.

6. Sutinen J. Interventions for managing antiretroviral therapy-associated lipoatrophy. Curr Opin Infect Dis. 2005;18(1):25-33.

7. Mallewa JE, Wilkins E, Vilar J, et al. HIV-associated lipodystrophy: a review of underlying mechanisms and therapeutic options. JAntimicrob Chemother. 2008;62(4):648-660.

8. Cohen G, Treherne A. Treatment of facial lipoatrophy via autologous fat transfer. J Drugs Dermatol. 2009;8(5):486-489.

9. Aquamid ${ }^{\circledR}$ (Injectable polyacrilamide gel). Prescribing information. 28 July 2005. Contura International; Soeberg, Denmark. Available from: http://www.aquamid.com/Web/Aquamid/Professional/ Professional//What+are+aquamid+injectable+implants.

10. Sculptra ${ }^{\circledR}$ (Iniectable poly-L-Lactic acid) Prescribing information. August 2004. Dermik Laboratories, Berwin PA, USA. Available from: http://www1.sculptra.com/US/hcp/PI.jsp.

11. Narciso P, Bucciardini R, Tozzi VK, et al. Immediate versus delayed surgical intervention for reconstructive therapy of HIV associated facial lipoatrophy. A randomized open label study. AIDS Res Hum Retroviruses. 2009;25(10):979-987.

12. Ascher B, Coleman S, Alster T, et al. Full scope of effect of facial lipoatrophy: a framework of disease understanding. Dermatol Surg. 2006;32:1058-1069.

13. Carr A, Law M. An objective lipodystrophy severity grading scale derived from the lipodystrophy case definition score. J Acquir Immune Defic Syndr. 2003;33:571.

14. Von Buelow S, Pallua N. Efficacy and safety of polyacrylamide hydrogel for facial soft-tissue augmentation in a 2-year follow-up: a prospective multicenter study for evaluation of safety and aesthetic results in 101 patients. Plast Reconstr Surg. 2006;118:85S-91S.

15. Moyle GJ, Lysakova L, Brown S, et al. A randomized open-label study of immediate versus delayed polylactic acid injections for the cosmetic management of facial lipoatrophy in persons with HIV infection. HIV Med. 2004;5:82-87. 
16. Huang SJ, Becerra K, Fernandez S, Lee D, Matthews WC. The impact of HIV-associated lipodistrophy on healthcare utilization and costs. Aids Res Ther. 2008;5:14.

17. Carey D, Liew S, Emery S. Restorative interventions for HIV facial lipoatrophy. AIDS Rev. 2008;10:116-124.

18. Lemperle G, Morhenn V, Charrier U. Human histology and persistence of various injectable filler substances for soft tissue augmentation. Aesthetic Plast Surg. 2003;27:354-366.
19. Guaraldi G, Orlando G, De Fazio D, et al. Comparison of three diffrent interventions for correction of HIV-associated facial lipoatrophy: a prospective study. Antiviral Ther. 2005;10:753-759.

\section{Publish your work in this journal}

Patient Preference and Adherence is an international, peer-reviewed, open access journal focusing on the growing importance of patient preference and adherence throughout the therapeutic continuum. Patient satisfaction, acceptability, quality of life, compliance, persistence and their role in developing new therapeutic modalities and compounds to optimize clinical outcomes for existing disease states are major areas of interest. This journal has been accepted for indexing on PubMed Central. The manuscript management system is completely online and includes a very quick and fair peer-review system. Visit http://www.dovepress.com/ testimonials.php to read real quotes from published authors.

Submit your manuscript here: http://www.dovepress.com/patient-preference-and-adherence-journal 